Published in final edited form as:

Obesity (Silver Spring). 2017 August ; 25(8): 1336-1342. doi:10.1002/oby.21889.

\title{
The Dietary Intervention to Enhance Tracking with mobile (DIET Mobile) study: A six-month randomized weight loss trial
}

\author{
Gabrielle M. Turner-McGrievy, PhD, MS, RD [Assistant professor], \\ Department of Health Promotion, Education, and Behavior, Arnold School of Public Health, \\ University of South Carolina, 915 Greene Street, Room 529, Columbia, SC 29208 USA \\ Sara Wilcox, PhD [Professor], \\ Department of Exercise Science, Director, Prevention Research Center, Arnold School of Public \\ Health, University of South Carolina, Columbia, SC USA
}

\begin{abstract}
Alycia Boutté, MPH [Doctoral student], Department of Health Promotion, Education, and Behavior, Arnold School of Public Health, University of South Carolina, 915 Greene Street, Room 529, Columbia, SC 29208 USA

\section{Brent E. Hutto, MSPH [Statistician],}

Prevention Research Center, Arnold School of Public Health, University of South Carolina, Columbia, SC USA
\end{abstract}

\section{Camelia Singletary, MPH,}

Arnold School of Public Health, Department of Health Promotion, Education, and Behavior, 915 Greene Street, Room 529, Columbia, SC 29208 USA

Eric R. Muth, PhD [Professor], and

Psychology, Clemson University, Clemson, SC USA

\section{Adam Hoover, PhD [Associate Professor] Holcombe Department of Electrical and Computer Engineering, Clemson University, Clemson, SC USA}

\author{
Abstract \\ Objective-To examine the use of two different mobile diet self-monitoring methods for weight \\ loss.
}

\footnotetext{
Users may view, print, copy, and download text and data-mine the content in such documents, for the purposes of academic research, subject always to the full Conditions of use:http://www.nature.com/authors/editorial_policies/license.html\#terms

Corresponding author and for reprint requests: Gabrielle M. Turner-McGrievy, PhD, MS, RD, Department of Health Promotion, Education, and Behavior, Arnold School of Public Health, University of South Carolina, 915 Greene Street, Room 529, Columbia, SC 29208 USA, brie@sc.edu.

Conflict of interest statement: Authors Adam Hoover and Erich Muth have formed a company, Bite Technologies, to market and sell a bite counting device. Clemson University owns a US patent for intellectual property known as "The Weight Watch", USA, Patent No. 8310368, filed January 2009, granted November 13, 2012. Bite Technologies has licensed the method from Clemson University. Adam Hoover and Eric Muth receive royalty payments from bite counting device sales. The remaining authors do not have any conflicts of interest to declare.

Author contributions: GTM, ERM, SW, and AWH conceived the project. Data acquisition and interpretation were conducted by GTM, AB, BEH, and CS. GTM and BEH performed the statistical analyses and implemented required custom software. AB and CS provided administrative support. GTM obtained funding for the study and wrote the manuscript. All authors provided critical revision of the manuscript and approved the final version.
} 
Methods-Overweight adults ( $\mathrm{n}=81$; mean BMI $34.7 \pm 5.6 \mathrm{~kg} / \mathrm{m}^{2}$ ) were randomized to selfmonitor their diet with a mobile app (App, $n=42$ ) or wearable Bite Counter device (Bite, $n=39$ ). Both groups received the same behavioral weight loss information via twice weekly podcasts. Weight, physical activity (International Physical Activity Questionnaire), and energy intake (2 dietary recalls) were assessed at 0,3 , and 6 months.

Results-At six months, $75 \%$ of participants completed the trial. The App group lost significantly more weight $(-6.8 \pm 0.8 \mathrm{~kg})$ than the Bite group $(-3.0 \pm 0.8 \mathrm{~kg}$; group $\times$ time interaction: $\mathrm{P}<0.001)$. Changes in energy intake $(-621 \pm 157 \mathrm{App},-456 \pm 167$ Bite; $\mathrm{P}=0.47)$ or number of days diet was tracked $(90.7 \pm 59.2 \mathrm{App}, 68.4 \pm 61.2 \mathrm{Bite} ; \mathrm{P}=0.09)$ did not differ between groups, but the Bite group had significant increases in physical activity METs min/wk (+2015.4 $\pm 684.6 ; \mathrm{P}=0.02)$ compared to little change in the App group (-136.5 $\pm 630.6 ; \mathrm{P}=0.02)$. Total weight loss was significantly correlated with number of podcasts downloaded $(\mathrm{r}=-0.33, \mathrm{P}<0.01)$ and number of days diet was tracked $(\mathrm{r}=-0.33, \mathrm{P}<0.01)$.

Conclusions-While frequency of diet tracking was similar between the App and Bite groups, there was greater weight loss observed in the App group.

\section{Keywords}

weight loss; mobile health; technology; diet; dietary self-monitoring

\section{Introduction}

One of the cornerstones of behavioral weight loss treatment is dietary self-monitoring (the systematic recording of foods and beverages consumed each day). ${ }^{1}$ Adherence to dietary self-monitoring has been associated with greater weight loss, ${ }^{2}$ but self-monitoring can be burdensome ${ }^{3}$ and decrease over time. ${ }^{2}$ Self-monitoring smartphone apps have the potential to make diet tracking easier and engaging, and therefore, improve weight loss. ${ }^{4}$ However, even use of apps may not prevent a decline in self-monitoring adherence. ${ }^{5}$ While use of electronic methods of dietary self-monitoring are promising, there is still a "law of attrition" that occurs in digital health interventions, where users discontinue use of technology-based components over time. ${ }^{6}$

Research has demonstrated that accuracy is not as important as frequency and adherence to self-monitoring for weight loss; ${ }^{7}$ therefore, finding ways to reduce burden to increase the frequency of self-monitoring may be more important than focusing on accurate and detailed methods. The field of mobile dietary self-monitoring has still primarily relied on apps that require a user to enter in foods/beverages consumed, either by typing in the names of items, using a barcode scanner, or taking a photograph of the item. ${ }^{8,9}$ In comparison to diet monitoring, mobile physical activity (PA) tracking has become much more objective and automated, allowing users to wear a device that tracks movement. ${ }^{10}$

The goal of the present study was to test a more automated approach to dietary selfmonitoring compared to a traditional diet self-monitoring app as part of a six-month, behavioral, randomized weight loss intervention. The Bite Counter is a wrist-worn device that monitors intake by counting bites through the use of a micro-electro-mechanical 
gyroscope. ${ }^{11}$ Users turn on the device at the start of eating and off at the end. During eating, it displays bite count for the current eating activity and allows users to review total bites consumed throughout the day. ${ }^{12}$ Because of the more automated nature of the Bite Counter device, we hypothesized that participants randomized to use the Bite Counter would lose significantly more weight by six months than those assigned to use a traditional diet mobile app.

\section{Methods}

The Dietary Intervention to Enhance Tracking with mobile devices (DIET Mobile) study was a six-month randomized weight loss trial comparing two different diet self-monitoring methods: traditional diet app (Calorie Counter by FatSecret) and wearable Bite Counter device. Overweight or obese (BMI $25-49.9 \mathrm{~kg} / \mathrm{m}^{2}$ ) adults, who were interested in losing weight, owned an Android or iPhone, were between the ages of 18 and 65 years, had a stable medical status (e.g., no uncontrolled thyroid conditions or diabetes), and were willing to accept random assignment, were recruited through worksite listserv messages, fliers, and newspaper ads. Participants attended an orientation session to complete a consent form and baseline questionnaires.

Questionnaires included demographic questions and the International Physical Activity Questionnaire (IPAQ), which assessed PA as an estimated metabolic equivalent (MET) of energy expenditure in minutes/week. ${ }^{13}$ Participants also completed a 24-hour dietary recall (representing a weekday) online using the Automated Self-Administered 24-hour Dietary Recall (ASA24TM). ${ }^{14}$ Participants were contacted after the orientation meeting to complete a second unannounced dietary recall (representing a weekend day) from their home or over the phone with study coordinators.

Once all participants completed baseline questionnaires, a study coordinator randomized them a group using a computerized random-number generator. Prior to revealing assignment, height and weight were assessed by trained assessors who were blinded to study condition at a research university. Weight was measured in light street clothes without shoes using a calibrated digital scale (SECA 869, Hamburg, Germany) accurate to $0.1 \mathrm{~kg}$. Height was measured using a stadiometer (SECA 213). Measures were assessed at baseline, three, and six months. The University of South Carolina Institutional Review Board approved the study, and all participants gave written informed consent. Participants received a \$20 incentive for completion of assessment activities at the three- and again at the six-month time-point.

\section{Intervention}

The DIET Mobile study was entirely remotely-delivered. Participants only attended inperson visits for data collection purposes. Regardless of group assignment, all participants received the same twice weekly podcasts. The podcasts, which have been used in previous weight loss research and are described elsewhere, ${ }^{15}, 16$ delivered the behavioral content of the program (based on Social Cognitive Theory ${ }^{17}$ and the Diabetes Prevention Program).${ }^{18}$ At the baseline assessment visit, participants were instructed on how to download and listen to the podcasts and received a test podcast to ensure their mobile device could download and 
play the files. Participants were emailed a link to a new podcast twice per week, allowing for objective assessment of podcast utilization. There were 48 total podcasts over the course of the six-month study. Participants were also informed of their group assignment: diet tracking mobile app (App group) or wearable Bite Counter (Bite group).

App group-Participants in the App group received an overview of the FatSecret ${ }^{\mathrm{TM}}$ app in their baseline assessment session. Participants downloaded the app and practiced entering a variety of foods and scanning bar codes of food products. Technical difficulties were addressed and participants informed study personnel of their FatSecret username. This allowed study personnel to use FatSecret's professional interface to track usage of the app. Participants were told to record all foods and beverages consumed each day in order to track total daily energy intake. In order to promote weight loss of one to two lbs/week, participants received a calorie goal for weight loss that has been successfully used in other behavioral weight loss studies (1200 kcal/d for participants weighing $\$ 90 \mathrm{~kg}, 1500 \mathrm{kcal} / \mathrm{d}$ for $91-112 \mathrm{~kg}$, and $1800 \mathrm{kcal} / \mathrm{d}$ for $\geq 113 \mathrm{~kg}$ ). ${ }^{19}$ Participants were also encouraged to selfmonitor their exercise by tracking steps. Participants were provided with a list of free pedometer apps or were given a pedometer (PEDUSA CW Step Pedometer) if they didn't want to use an app ( $\mathrm{n}=3$ requested one).

Bite group-Bite participants received a Bite Counter device and an overview of how to use the device at their baseline assessment session. The Bite Counter looks like a watch, displays digital time when not in use, and has a face that is square measuring 1.25 " on each side. Participants were shown how to download software to their work or home computer that would allow syncing/uploading of their Bite Counter data for objective tracking. Alternatively, participants could attend a monthly in-person visit to have a study staff member sync their device ( $\mathrm{n}=4$ chose this). Participants practiced using the Bite Counter by eating a snack and learning how to turn the device on and off and view bites. Participants were instructed to wear the device on their dominant hand and to use their non-dominant hand to drink non-caloric beverages, such as diet soda. Technical difficulties (syncing issues, assuring display time was correct, etc.) were addressed during this session and participants were told to turn on the device at the beginning of an eating session and off when finished. Similar to the App group, Bite group participants received a personalized bites/day goal based on the same kcal/d goal for the App group. Inspired by the Mifflin-St Jeor formula used to calculate resting metabolic rate, ${ }^{20}$ previous work developed a formula that predicts an individual's kilocalories per bite (KPB) based upon demographic variables: KPB (male) = 0.0967 height $(\mathrm{cm})+0.0992$ weight $(\mathrm{kg})-0.2478$ age; KPB $($ female $)=0.0528$ height $(\mathrm{cm})$ +0.0640 weight $(\mathrm{kg})-0.0534$ age. These equations were developed using previous freeliving data where participants wore the Bite Counter for two weeks, recording caloric intake using the ASA24. ${ }^{21}$ With this formula, kcals consumed can be estimated as kcals = bites $\times$ $\mathrm{KPB}$. This formula was tested on a separate dataset of 273 individuals eating a meal in a cafeteria, finding it to estimate calories consumed in an individual meal to $\pm 50 \mathrm{kcals}$, with no differences in KPB among normal, overweight, or obese individuals. ${ }^{22}$ The device has been shown to accurately detect bites with a sensitivity of $75 \%$ and a positive predictive value of $89 \% .{ }^{23}$ In a two-week validation study, 77 participants wore the Bite Counter to assess all eating occasions and participants also completed a 24-hour dietary recall each day. 
Mean daily bite count and daily kcals within each person were moderately correlated at 0.53. ${ }^{21}$ In addition to tracking bites, the Bite Counter also had a built-in pedometer, which tracked steps taken each day, and participants were encouraged to use this feature to selfmonitor exercise.

Both groups-The kcal/d and bites/d goals for both groups were provided as a starting estimate. If weight loss was less than $0.5 \mathrm{lbs} /$ week, target goals were decreased in order to promote weight loss. Number of days diet was tracked was objectively assessed during the study for both groups (via professional interface for FatSecret or examining usage of Bite Counter via a researcher interface). A day of tracking was operationalized as a participant having tracked any food or beverage on their app for the day or logging any bites with their Bite Counter, which is a similar method used in other weight loss studies. ${ }^{24-27}$ There were 168 possible days that diet could be self-monitored.

\section{Statistical analyses}

For differences in baseline characteristics, independent samples $t$ tests were used for continuous variables and chi-square test of independence was used for categorical data and differences between groups for achieving 5\% weight loss and meeting recommended energy goals. Intent-to-treat analysis was conducted. Repeated measures models were estimated for weight and other outcomes using PROC MIXED in SAS. The models included time, group, and a time $\times$ group interaction with no other covariates. The full information from the available data was used in each model to provide unbiased estimates of the treatment effect in the presence of attrition at the three- and six-month time points. Contrasts were constructed comparing weight loss (or change in other outcomes) at three and six months between groups. For comparing groups on number of podcasts downloaded and days with diet recorded, simple unadjusted $t$ tests were used.

A similar previous six-month trial was used to conduct sample size calculations ( $\alpha=0.05$ and power $1-\beta=80 \%$ ) based on expected differences between groups in self-monitoring frequency. ${ }^{15}$ In that study, participants who self-monitored for a mean of six days per week $(n=10)$ lost a mean of $11.6 \pm 7.1 \%$ body weight as compared to those who self-monitored a mean of three days per week $(n=12)$ who lost $2.8 \pm 4.1 \%$ body weight, corresponding to an effect size of 1.5 and seven participants needed per group. However, it was anticipated that the differences in self-monitoring frequency may be lower. Therefore, we also compared weight loss between those who self-monitored for two days per week or less (which was the study mean for self-monitoring frequency; $-0.4 \pm 3.6 \%$ weight loss) and those who selfmonitored more than two days per week $(-5.8 \pm 5.8 \%)$, which corresponded to an effect size of 0.53 and 45 per group. Allowing for $20 \%$ attrition at six months gave us a minimum of 17 participants for a large effect size and 108 for a moderate effect size.

\section{Results}

Data were collected between 2015 and 2016. There were 306 individuals who completed a screening questionnaire online (Figure 1), of which 164 were excluded (primarily for being unable to contact them), 142 were invited to orientation, and 81 completed all baseline assessments and were randomized to either the Bite $(n=39)$ or App group ( $n=42)$. Attrition 
was $16 \%$ at three-months and $25 \%$ at six-months and did not differ between groups at either three $\left(\chi^{2}=0.51, \mathrm{P}=0.48\right)$ or six months $\left(\chi^{2}=0.11, \mathrm{P}=0.75\right)$. Baseline characteristics did not differ between groups (Table 1). There were no differences in age, baseline body mass index (BMI), sex, or race between those who completed the study and those who did not attend the six-month assessment ( $\mathrm{P}$ 's all $>0.05)$. The majority of participants $(45 \%)$ were assigned a $1500 \mathrm{kcal} / \mathrm{d}$ (or equivalent bite amount) limit, followed by $38 \%$ for $1200 \mathrm{kcal} / \mathrm{d}$ and $17 \%$ for an $1800 \mathrm{kcal} / \mathrm{d}$ limit. At six months, there was no difference in those who met there recommended kcal goal (based on dietary recalls) between the App (38\%) vs. Bite (21\%; $\left.\chi^{2}=3.0, \mathrm{P}=0.08\right)$.

Results are presented as means \pm SE. Examining both groups combined, participants lost significant weight at both three $(-3.7 \pm 0.5 \mathrm{kgs} ; \mathrm{P}<0.001)$ and six months $(-4.9 \pm 0.5 \mathrm{kgs}$; $\mathrm{P}<0.001$ ). Weight loss over the study period was significantly different between groups at six but not at three months (Table 2). At six months, the App group lost significantly more weight $(-6.8 \pm 0.8 \mathrm{~kg})$ compared to the Bite group $(-3.0 \pm 0.8 \mathrm{~kg}$; group $\times$ time interaction: $\mathrm{p}<$. 001). In addition, significantly more App group participants achieved a 5\% weight loss at 6 months $(n=18,43 \%)$ than in the Bite group $\left(n=8,21 \% ; \chi^{2}=4.6, P=0.03\right)$. Examining withingroup changes, both groups achieved significant weight loss at both three and six months. Interestingly, changes in reported energy intake did not differ by group at either three or six months; however, reported energy expenditure did differ. The Bite group had significant increases in reported PA METs min/wk (+2015.4 $\pm 684.6 ; \mathrm{P}=0.02)$ with little change in the App group (-136.5 $\pm 630.6 ; \mathrm{P}=0.02)$.

Use of intervention components was also examined (Table 2). There were no differences in total number of podcasts downloaded or days diet was self-monitored between groups indicating equal levels of engagement in intervention-related activities. Weight loss at six months was significantly and moderately correlated with the number of podcasts downloaded $(\mathrm{r}=-0.33, \mathrm{P}<0.01)$ and the number of days diet was tracked $(\mathrm{r}=-0.33, \mathrm{P}<0.01)$. These correlations were also examined in a two-variable regression model that indicated a combined R-squared of 0.13 for number of podcasts and days diet was tracked as simultaneous predictors of six-month weight loss. Standardized beta coefficients were -0.20 for number of podcasts downloaded and -0.20 for days diet recorded with the combined effect statistically significant ( $\mathrm{p}=0.02)$. Interpretation of this simultaneous effect is difficult due to the moderately strong correlation $(\mathrm{r}=0.67, \mathrm{P}<0.01)$ between the predictors, but the correlation coefficients and standardized betas are both very similar, indicating both factors influenced weight loss.

\section{Discussion}

Mobile health approaches to obesity treatment have the potential to reach a larger population than traditional face-to-face approaches ${ }^{4}$ so it is important to include dietary self-monitoring approaches that are evidence-based, easy-to-use, and engaging. ${ }^{28,29}$ The present study examined two different approaches to dietary self-monitoring: mobile app and wearable Bite Counter. The study's primary hypothesis was that the Bite group would self-monitor their diet more frequently and, in turn, would lose more weight than the App group. The present study did not confirm the primary hypothesis-in fact, the results were in the opposite 
direction. The App group lost significantly more weight than the Bite group with no differences in self-monitoring frequency. There were no differences in reported energy intake; however reported energy expenditure did differ, favoring the Bite group. The Bite group was told to use the built-in pedometer in their Bite Counter, while the App group was provided with a list of free pedometer apps or a wearable pedometer. It is possible that because the pedometer was already built into the Bite Counter device, the Bite group was able to self-monitor PA more effectively, without the requirement of another app or device. There was also no difference between groups in number of podcasts downloaded, indicating that each group received the behavioral content of the intervention at equal rates. In addition, there were no differences in frequency of diet self-monitoring days, indicating that participants adhered to diet self-monitoring equally. However, frequency of self-monitoring and number of podcasts downloaded both appeared to be important for weight loss, regardless of group assignment.

There are a few possible reasons why the App group lost more weight than the Bite group. One reason could be due to difficulty with using the Bite Counter, which required participants to remember to turn on and off the device at each eating occasion. Participants frequently mentioned that they either forgot to turn the device on or left the device on well after eating. The inability to edit this data may have left some participants frustrated and less willing to regularly use it. Another reason is it is possible that bite limits were not accurate to promote weight loss. Although personalized limits were calculated based on prior research and bite limits were adjusted based on rate of weight loss, the limits may not have been low enough to promote adequate weight loss. Lastly, tracking energy intake may be a more sensitive feedback mechanism for behavior than tracking bite intake as the energy amount per bite can greatly vary. ${ }^{23}$ It's possible that App participants changed the content of their diet more than the Bite group. However, both groups received the same dietary advice via podcast and both reported similar changes in energy intake.

While the App group lost more weight, both groups lost more weight than was observed in a previous six-month weight loss study examining the use of similar podcasts comparing paper journal diet tracking to FatSecret tracking. ${ }^{15}$ In that study, there was no difference between groups with both groups losing a mean of $2.4 \mathrm{~kg}$, which is less than what was observed in either the Bite or App group. In the present study, participants knew their use of the Bite Counter or the App was being regularly monitored by study personnel, something that was not possible in the previous study. ${ }^{15}$ Therefore, weight loss was potentially higher in the present study due to participants knowing their self-monitoring behavior was being observed, which can impact behavior. ${ }^{30}$ The "Hawthorne effect," which has been understudied in the area of diet-related behaviors and weight loss, has the potential to impact adherence to recommended behaviors. For example, a previous study found that people use less electricity in their homes just by being reminded they are in a study about electricity use. ${ }^{31}$ In addition, the weight loss observed in both groups was greater than what has been observed in many other mobile app-based weight loss interventions. ${ }^{32,33}$ One meta-analysis examined both mobile (text messaging, apps, etc.) and web-based electronic health (eHealth) weight loss interventions. ${ }^{33}$ Relevant to the present study, authors of the meta-analysis compared weight loss between participants assigned to a standard eHealth intervention versus eHealth with additional features ( $\mathrm{n}=13$ studies) finding the additional features led to a 
mean difference of $1.46 \mathrm{~kg}$ greater loss. ${ }^{33}$ Of those 13 studies, the majority observed weight losses that were less than what was observed in the present study. ${ }^{33}$ In addition, frequency of dietary self-monitoring was similar in the present study (54\% adherent App, $41 \%$ adherent Bite) to other studies using eHealth approaches, finding the percentage of number of days adherent range between $53-60 \% .^{24-27}$

Regardless of method used, frequency of diet tracking was associated with weight loss. Future studies should consider offering participants a variety of choices for dietary selfmonitoring or try multiple options simultaneously. Providing participants with the opportunity to try several self-monitoring methods may increase user control and decrease cognitive load, both of which have been shown to mediate the relationship between a remotely-delivered weight loss intervention and weight loss outcomes. ${ }^{34}$

\section{Study strengths and limitations}

The present study has several strengths. The study compared two active conditions with differing types of feedback using two different mobile methods of dietary self-monitoringthe Bite Counter device was compared to a more traditional mobile app self-monitoring method for diet tracking. Objective data were used to assess device usage, podcast downloads, and weight loss and data assessors were blinded to condition. The present study also has some limitations. Self-report was used for PA and use of more objective measures (e.g., accelerometers) would have strengthened this assessment. Energy intake may have been underreported. ${ }^{35}$ Recruitment was a challenge even using varying recruitment methods. The study fell short of recruiting 108 participants, despite having 142 participants invited to orientation. This was potentially due to a historic flood that occurred in town during the fall of 2015 as recruitment began. ${ }^{36}$ Secondary outcomes (energy intake and PA) may have been underpowered to detect differences. In addition, a 20\% attrition rate was expected at six months and the study saw a slightly higher attrition rate of $25 \%$. While attrition was greater than was intended, $25 \%$ attrition is similar to what has been observed in several other remotely-delivered weight loss interventions. ${ }^{37-39}$ No differential attrition rates were observed between groups in the present study.

\section{Conclusion}

Dietary self-monitoring is an important component of behavioral weight loss interventions, ${ }^{1}$ but self-monitoring can be burdensome ${ }^{3}$ and decline over time. ${ }^{2}$ Therefore, finding ways to make dietary self-monitoring easier and more engaging may improve adherence rates, and in turn, improve weight loss outcomes. Alternately, it is possible that passive monitoring (e.g., Bite Counter) is not as engaging as more active monitoring that requires regularly entering foods. Previous research has indicated that frequent checking of an app can lead to habit formation and more sustained usage. ${ }^{40}$ This active monitoring may have allowed for App group participants to create a more long-term diet tracking habit and be more engaged.

The present study examined two potential options for dietary self-monitoring, finding both App and Bite groups self-monitored at equal rates with greater weight loss in the App group. Both groups lost weight, however, so future studies should consider providing participants 
with a choice of self-monitoring methods in order to take preference into account and improve adherence.

\section{Acknowledgments}

Funding source: This study was funded by the National Cancer Institute of the National Institutes of Health under award number R21CA18792901A1 (PI: Turner-McGrievy). The content is solely the responsibility of the authors and does not necessarily represent the official views of the National Institutes of Health.

\section{References}

1. Butryn ML, Webb V, Wadden TA. Behavioral treatment of obesity. Psychiatr Clin North Am. 2011; 34(4):841-859. [PubMed: 22098808]

2. Burke LE, Wang J, Sevick MA. Self-monitoring in weight loss: a systematic review of the literature. J Am Diet Assoc. 2011; 111(1):92-102. [PubMed: 21185970]

3. Burke LE, Swigart V, Warziski Turk M, Derro N, Ewing LJ. Experiences of self-monitoring: successes and struggles during treatment for weight loss. Qual Health Res. 2009; 19(6):815-828. [PubMed: 19365099]

4. Thomas JG, Bond DS. Review of Innovations in Digital Health Technology to Promote Weight Control. Current Diabetes Reports. 2014; 14(5):485. [PubMed: 24664797]

5. Turner-McGrievy GM, Beets MW, Moore JB, Kaczynski AT, Barr-Anderson DJ, Tate DF. Comparison of traditional versus mobile app self-monitoring of physical activity and dietary intake among overweight adults participating in an mHealth weight loss program. J Am Med Inform Assoc. 2013; 20(3):513-518. [PubMed: 23429637]

6. Eysenbach G. The Law of Attrition. J Med Internet Res. 2005; 7(1):e11. [PubMed: 15829473]

7. Yon BA, Johnson RK, Harvey-Berino J, Gold BC. The Use of a Personal Digital Assistant for Dietary Self-Monitoring Does Not Improve the Validity of Self-Reports of Energy Intake. J Am Diet Assoc. 2006; 106(8):1256-1259. [PubMed: 16863723]

8. Hales S, Dunn C, Wilcox S, Turner-McGrievy GM. Is a picture worth a thousand words? Few evidence-based features of dietary interventions included in photo diet tracking mobile apps for weight loss. Journal of Diabetes Science and Technology. 2016; 10(6):1399-1405. [PubMed: 27251127]

9. Pagoto S, Schneider K, Jojic M, DeBiasse M, Mann D. Evidence-Based Strategies in Weight-Loss Mobile Apps. Am J Prev Med. 2013; 45(5):576-582. [PubMed: 24139770]

10. Evenson KR, Goto MM, Furberg RD. Systematic review of the validity and reliability of consumer-wearable activity trackers. The International Journal of Behavioral Nutrition and Physical Activity. 2015; 12:159. [PubMed: 26684758]

11. Dong Y, Hoover A, Scisco J, Muth E. A new method for measuring meal intake in humans via automated wrist motion tracking. Appl Psychophysiol Biofeedback. 2012; 37(3):205-215. [PubMed: 22488204]

12. Scisco JL, Muth ER, Dong Y, Hoover AW. Slowing Bite-Rate Reduces Energy Intake: An Application of the Bite Counter Device. J Am Diet Assoc. 2011; 111(8):1231-1235. [PubMed: 21802572]

13. Hagstromer M, Oja P, Sjostrom M. The International Physical Activity Questionnaire (IPAQ): a study of concurrent and construct validity. Public Health Nutr. 2006; 9(6):755-762. [PubMed: 16925881]

14. Subar AF, Crafts J, Zimmerman TP, et al. Assessment of the accuracy of portion size reports using computer-based food photographs aids in the development of an automated self-administered 24hour recall. J Am Diet Assoc. 2010; 110(1):55-64. [PubMed: 20102828]

15. Turner-McGrievy G, Tate D. Tweets, Apps, and Pods: Results of the 6-Month Mobile Pounds Off Digitally (Mobile POD) Randomized Weight-Loss Intervention Among Adults. J Med Internet Res. 2011; 13(4):e120. [PubMed: 22186428] 
16. Turner-McGrievy GM, Campbell MK, Tate DF, Truesdale KP, Bowling JM, Crosby L. Pounds Off Digitally study: a randomized podcasting weight-loss intervention. Am J Prev Med. 2009; 37(4): 263-269. [PubMed: 19765496]

17. Bandura A. Health promotion by social cognitive means. Health Educ Behav. 2004; 31(2):143164. [PubMed: 15090118]

18. DPP. The Diabetes Prevention Program (DPP). Diabetes Care. 2002; 25(12):2165-2171. [PubMed: 12453955]

19. Jakicic JM, Tate DF, Lang W, et al. Effect of a stepped-care intervention approach on weight loss in adults: A randomized clinical trial. JAMA. 2012; 307(24):2617-2626. [PubMed: 22735431]

20. Mifflin MD, St Jeor ST, Hill LA, Scott BJ, Daugherty SA, Koh YO. A new predictive equation for resting energy expenditure in healthy individuals. The American Journal of Clinical Nutrition. 1990; 51(2):241-247. [PubMed: 2305711]

21. Scisco J, Muth E, Hoover A. Examining the Utility of a Bite-Count Based Measure of Eating Activity in Free-Living Humans. Journal of the Academy of Nutrition and Dietetics. 2013; 114(3): 464-469. [PubMed: 24231364]

22. Salley, J. Accuracy of a bite-count based calorie estimate compared to human estimates with and without calorie information available. All Theses. 2013. Paper 1680. http:// tigerprints.clemson.edu/all_theses/1680

23. Shen Y, Salley J, Muth E, Hoover A. Assessing the Accuracy of a Wrist Motion Tracking Method for Counting Bites across Demographic and Food Variables. IEEE J Biomed Health Inform. 2016

24. Helsel DL, Jakicic JM, Otto AD. Comparison of techniques for self-monitoring eating and exercise behaviors on weight loss in a correspondence-based intervention. J Am Diet Assoc. 2007; 107(10): 1807-1810. [PubMed: 17904942]

25. Tate DF, Jackvony EH, Wing RR. A randomized trial comparing human e-mail counseling, computer-automated tailored counseling, and no counseling in an Internet weight loss program. Arch Intern Med. 2006; 166(15):1620-1625. [PubMed: 16908795]

26. Tate DF, Wing RR, Winett RA. Using Internet technology to deliver a behavioral weight loss program. JAMA. 2001; 285(9):1172-1177. [PubMed: 11231746]

27. Yon BA, Johnson RK, Harvey-Berino J, Gold BC, Howard AB. Personal digital assistants are comparable to traditional diaries for dietary self-monitoring during a weight loss program. J Behav Med. 2007; 30(2):165-175. [PubMed: 17216341]

28. Bardus M, van Beurden SB, Smith JR, Abraham C. A review and content analysis of engagement, functionality, aesthetics, information quality, and change techniques in the most popular commercial apps for weight management. Int J Behav Nutr Phys Act. 2016; 13:35. [PubMed: 26964880]

29. Coons MJ, DeMott A, Buscemi J, et al. Technology Interventions to Curb Obesity: A Systematic Review of the Current Literature. Current Cardiovascular Risk Reports. 2012; 6(2):120-134. [PubMed: 23082235]

30. Jacko, JA., editor. Human Computer Interaction Handbook: Fundamentals, Evolving Technologies, and Emerging Applications. Third Edition. Boca Raton, FL: CRC Press; 2012.

31. Schwartz D, Fischhoff B, Krishnamurti T, Sowell F. The Hawthorne effect and energy awareness. Proc Natl Acad Sci U S A. 2013; 110(38):15242-15246. [PubMed: 24003110]

32. Flores Mateo G, Granado-Font E, Ferre-Grau C, Montana-Carreras X. Mobile Phone Apps to Promote Weight Loss and Increase Physical Activity: A Systematic Review and Meta-Analysis. J Med Internet Res. 2015; 17(11):e253. [PubMed: 26554314]

33. Hutchesson MJ, Rollo ME, Krukowski R, et al. eHealth interventions for the prevention and treatment of overweight and obesity in adults: a systematic review with meta-analysis. Obes Rev. 2015; 16(5):376-392. [PubMed: 25753009]

34. Ko LK, Campbell MK, Lewis MA, Earp JA, DeVellis B. Information Processes Mediate the Effect of a Health Communication Intervention on Fruit and Vegetable Consumption. Journal of Health Communication. 2010; 16(3):282-299.

35. Ma Y, Olendzki BC, Pagoto SL, et al. Number of 24-Hour Diet Recalls Needed to Estimate Energy Intake. Ann Epidemiol. 2009; 19(8):553-559. [PubMed: 19576535] 
36. Holmes, RUS. [Accessed May 18, 2016] Geological Survey. 2015. http://water.usgs.gov/floods/ events/2015/Joaquin/HolmesQA.html

37. Krukowski RA, Tilford JM, Harvey-Berino J, West DS. Comparing Behavioral Weight Loss Modalities: Incremental Cost-Effectiveness of an Internet-Based Versus an In-Person Condition. Obesity. 2011; 19(8):1629-1635. [PubMed: 21253001]

38. Pellegrini CA, Verba SD, Otto AD, Helsel DL, Davis KK, Jakicic JM. The comparison of a technology-based system and an in-person behavioral weight loss intervention. Obesity (Silver Spring). 2012; 20(2):356-363. [PubMed: 21311506]

39. Lyzwinski L. A Systematic Review and Meta-Analysis of Mobile Devices and Weight Loss with an Intervention Content Analysis. Journal of Personalized Medicine. 2014; 4(3):311. [PubMed: 25563356]

40. Oulasvirta A, Rattenbury T, Ma L, Raita E. Habits make smartphone use more pervasive. Personal and Ubiquitous Computing. 2012; 16(1):105-114. 


\section{Study Importance Questions}

\section{What is already known about this subject?}

- Dietary self-monitoring is important for weight loss, but adherence can decline over time.

- Mobile methods of diet tracking hold promise as a way to engage individuals to track their diet for a longer period of time.

- $\quad$ Little is known about how various mobile diet tracking methods impact engagement and weight loss.

\section{What does your study add?}

- $\quad$ The present study compared two different diet tracking methods (App vs. Bite Counter) for weight loss finding greater weight loss in the App group.

- The findings show that significant weight loss can be produced with an entirely eHealth approach.

- The findings also show that no matter which device people used, frequency of diet self-monitoring was associated with weight loss. 


\section{DIET Mobile CONSORT Flow Diagram}

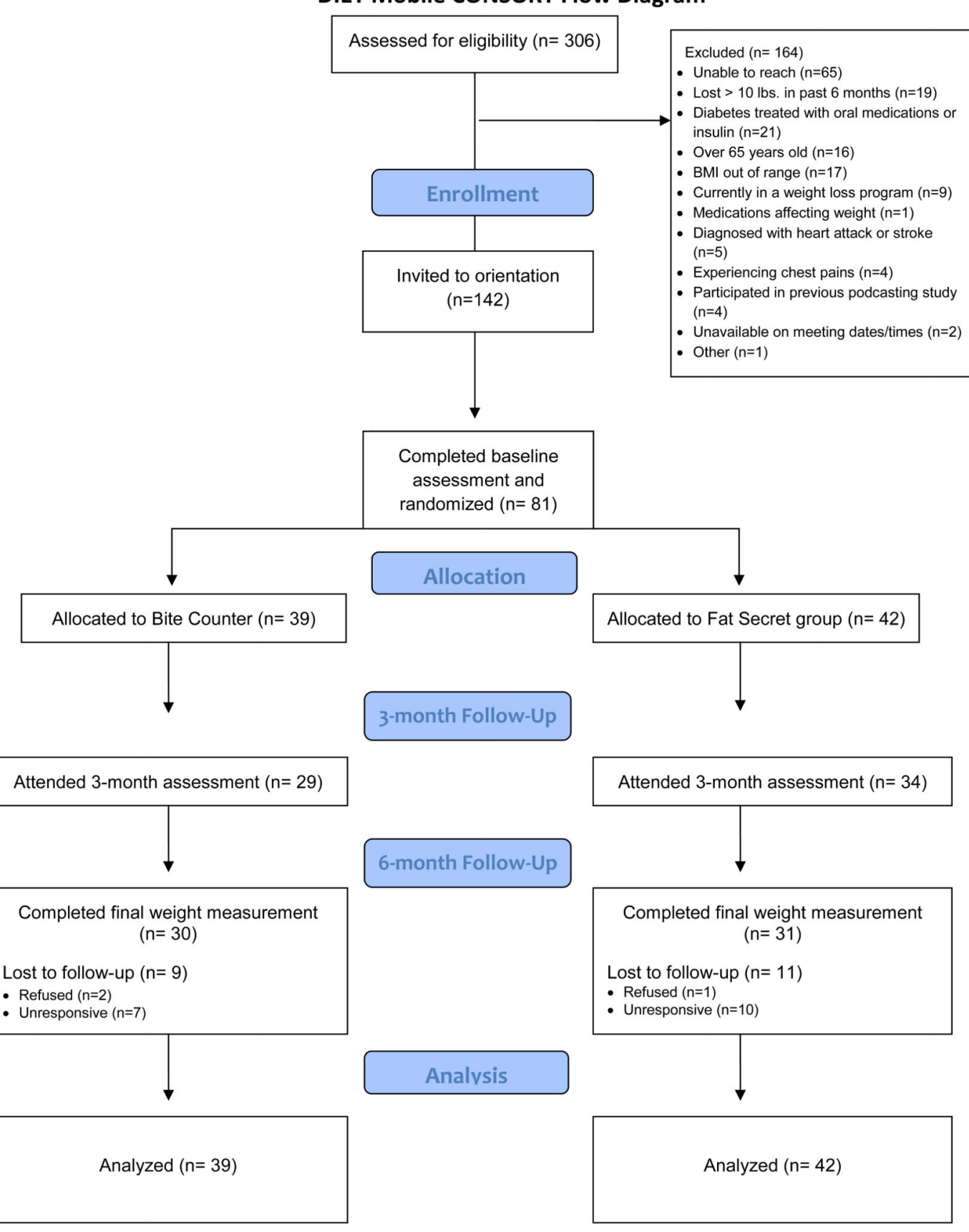

Figure 1. DIET Mobile CONSORT Flow Diagram 
Table 1

Baseline demographics and body mass index of study participants in the DIET Mobile Study

\begin{tabular}{|c|c|c|c|}
\hline & App Group & Bite Group & P-value for difference among groups \\
\hline$n$ & 42 & 39 & \\
\hline Mean age $( \pm$ SD) & $48.6 \pm 11.7$ & $47.5 \pm 12.3$ & 0.68 \\
\hline Gender $(\%)$ & & & 0.88 \\
\hline Female & $35(83.3 \%)$ & $32(82.1 \%)$ & \\
\hline Male & $7(16.7 \%)$ & $7(17.9 \%)$ & \\
\hline Race (\%) & & & 0.90 \\
\hline Black & $6(14.3 \%)$ & $7(17.9 \%)$ & \\
\hline White & $35(83.3 \%)$ & $31(79.5 \%)$ & \\
\hline Other & $1(2.4 \%)$ & $1(2.6 \%)$ & \\
\hline Education (\%) & & & 0.50 \\
\hline High school or some college & $5(11.9 \%)$ & $7(18 \%)$ & \\
\hline College graduate & $18(42.9 \%)$ & $19(48.7 \%)$ & \\
\hline Advanced degree & $19(45.2 \%)$ & $13(33.3 \%)$ & \\
\hline Occupation (\%) & & & $\mathrm{P}=0.20$ \\
\hline No current employment & $2(4.8 \%)$ & $1(2.6 \%)$ & \\
\hline Service Occupation & $5(11.9 \%)$ & $4(10.3 \%)$ & \\
\hline Technical, sales, administrative & $4(9.5 \%)$ & $9(23.1 \%)$ & \\
\hline Executive, managerial & $2(4.8 \%)$ & $3(7.7 \%)$ & \\
\hline Professional specialty & $17(40.5 \%)$ & $7(17.9 \%)$ & \\
\hline Retired & $4(9.5 \%)$ & $2(5.1 \%)$ & \\
\hline Other & $8(19 \%)$ & $13(33.3 \%)$ & \\
\hline Marital Status (\%) & & & 0.16 \\
\hline Married & $29(69 \%)$ & $21(53.8 \%)$ & \\
\hline Other & $13(31 \%)$ & $18(46.2 \%)$ & \\
\hline Mean BMI $\left(\mathrm{kg} / \mathrm{m}^{2}\right)( \pm \mathrm{SD})$ & $33.4 \pm 4.8$ & $33.4 \pm 5.7$ & 0.97 \\
\hline Energy intake (kcal/d) $( \pm$ SD) & $2190 \pm 886$ & $2264 \pm 925$ & 0.71 \\
\hline
\end{tabular}


Table 2

Weight loss and other outcomes by group presented as means (standard error)

\begin{tabular}{|c|c|c|c|}
\hline & $\underset{(n=42)}{\text { App Group }}$ & $\begin{array}{c}\text { Bite Group } \\
(\mathbf{n}=39)\end{array}$ & $\begin{array}{l}\text { P-value for difference } \\
\text { between groups } a\end{array}$ \\
\hline \multicolumn{4}{|l|}{ Weight change (kg) } \\
\hline 3 months & $-4.7(0.7)^{a}$ & $-2.8(0.8)^{a}$ & 0.07 \\
\hline 6 months & $-6.8(0.8)^{a}$ & $-3.0(0.8)^{a}$ & 0.001 \\
\hline \multicolumn{4}{|l|}{ Change in energy intake (kcals/day) } \\
\hline 3 months & $-761.4(147.3)^{a}$ & $-479.8(158.8) b$ & 0.20 \\
\hline 6 months & $-620.7(157.3)^{a}$ & $-456.2(166.9) b$ & 0.47 \\
\hline \multicolumn{4}{|l|}{ Change in total Metabolic Equivalents (METs minutes/week) } \\
\hline 3 months & $+675.5(590.5)$ & $+1321.1(639.6)^{c}$ & 0.46 \\
\hline 6 months & $-136.5(630.6)$ & $+2015.4(684.6) b$ & 0.02 \\
\hline Total number of podcasts downloaded (out of 48 episodes) & $31.0(2.7)$ & $26.1(2.8)$ & 0.22 \\
\hline Total number of days diet was recorded (out of 168 possible days) & $90.7(59.2)$ & $68.4(61.2)$ & 0.09 \\
\hline
\end{tabular}

${ }^{a} \mathrm{P}<0.001$ for within-group changes for App or Bite group participants

$b_{\mathrm{P}<0.01 \text { for within-group changes for App or Bite group participants }}$

${ }_{\mathrm{P}}^{c}<0.01$ for within-group changes for App or Bite group participants 